\title{
Drones, Gulls and Urbanity: Interaction between New Technologies and Human Subsidized Species in Coastal Areas
}

\author{
Martín G. Frixione $^{1}$ (D) and Christian Salvadeo ${ }^{2, *}$ \\ 1 CENPAT-CESIMAR, CONICET, Puerto Madryn 9120, Argentina; mfpatagonia@gmail.com \\ 2 CONACYT-Universidad Autónoma de Baja California Sur, La Paz 23080, Mexico \\ * Correspondence: csalvadeo@uabcs.mx
}

check for updates

Citation: Frixione, M.G.; Salvadeo, C. Drones, Gulls and Urbanity:

Interaction between New

Technologies and Human Subsidized Species in Coastal Areas. Drones 2021, 5,30. https://doi.org/10.3390/ drones5020030

Academic Editor: David R. Green

Received: 26 March 2021

Accepted: 19 April 2021

Published: 22 April 2021

Publisher's Note: MDPI stays neutral with regard to jurisdictional claims in published maps and institutional affiliations.

Copyright: (c) 2021 by the authors. Licensee MDPI, Basel, Switzerland. This article is an open access article distributed under the terms and conditions of the Creative Commons Attribution (CC BY) license (https:// creativecommons.org/licenses/by/ $4.0 /)$.

\begin{abstract}
The use of drones has expanded the boundaries of several activities, which is expected to be utilized intensively in the near future. Interactions between urbanity and naturalness have been increasing while urban expansion amplifies the proximity between urban and natural areas. In this scenario, the interactions between drones and fauna could be augmented. Therefore, the aim of this study was to depict and evaluate the responses of the opportunistic and territorial seagull Larus livens to a small-sized drone during the non-breeding stage in urban areas and natural surroundings. The results evidenced that gulls do not react to drone sounds, coloration, or distance between them and the drone take-off spot. Clearly, the take-off vertical movement triggers an agonistic behavior that is more frequent in groups conformed by two adults, evidencing some kind of territorial response against the device, expressed as characteristic mobbing behavior. Thus, adult settled gulls in touristic and non-urbanized areas displayed agonistic behavior more frequently against the drone. Despite the coastal urban area being a free interaction environment, it evidences a low risk between drone management and territorial seabirds.
\end{abstract}

Keywords: Larus livens; unmanned aircraft vehicles; mobbing behavior; natural areas; Gulf of California

\section{Introduction}

The use of drones has been expanding the frontiers of scientific knowledge and other several activities, facilitating and improving procedures throughout numerous fields [1,2], among which are agriculture [3,4], ecological studies [5,6], nature photography [7], fisheries [8], disaster management and civil security applications [9], commercial delivery [10], and medical care activities [11]. For example, drones have been shown to be promissory tools for improving health care purposes such as transporting blood for transfusions, testing in pandemics, and other infectious disease matters [11,12]. Additionally, ecological studies about population dynamics and landscape imaging are among the most numerous activities utilizing drones as a revolutionary tool in science [13].

The prompt global urban expansion is amplifying the proximity between urban and natural protected areas, increasing the edges and interactions between urbanity and naturalness [14]. In this scenario, the interactions triggered by unmanned aircraft vehicles (UAVs) on wildlife could be augmented throughout the enlarged edges while natural patches become included in the expanded urban matrix. Interactions may become more complex in coastal cities where several kinds of habitats and species (terrestrial and marine) occur and drones are expected to be used intensively for recreational, research, commercial, and health care purposes in the near future [15].

Several reactions have been recorded in wildlife in response to drones; some species ignore the presence of UAVs completely [16], and others react by evading [17] or confronting them, attacking the flying device in their territories aggressively [18]. Urban and semi-urban are the most utilized areas for UAVs because of the high density human population and connectivity facilities. However, natural areas in close surroundings could 
also be utilized intensively in the short term for recreational imaging and for some health care purposes in rural areas [19]. The lack of zoning analyses about potential risks for this kind of technology makes geographic information necessary to determine safe areas where UAVs could transit in the near future, which also imply no risk to wildlife.

As previously mentioned, interactions between wildlife and drones are expected to increase mostly with birds as the main actors because drones use the aerial space where they could spend most of their time foraging, monitoring, and defending territories for food or from predators. Most birds (especially colonial seabirds) are central foragers during the breeding stage, scattering for different energetic requirements once they are released from parental duties during post-breeding. The breeding season is a short-term process but intense in most seabirds, whereas the non-breeding period is a longer lapse when birds spread outside their central breeding territories. Available research using drones in waterbird ecology have been conducted mostly during breeding stages, especially those focusing on colonial seabirds [20,21], probably in response to the complexity of conducting research after individual dispersion during post-breeding. In this regard, responses to drones have been evaluated in colonial seabirds only during breeding [17,22], but information about the reactions of aggressive seabirds as gulls against drones are scarce during breeding [18] and unknown during non-breeding seasons, respectively.

Among aggressive seagulls, the Yellow-footed gull (Larus livens) the largest one in America is endemic to the Gulf of California and breeds in a few colonies within several islands of the Sea of Cortez $[23,24]$. This species is the only large white-headed gull that breeds in the subtropical zone, nesting in desert islands under hot and dry conditions [23, 25]. As other opportunistic large gulls, the species is omnivorous, taking advantage of intertidal invertebrates, human garbage, and artisanal fishery discards in coastal areas [26]. Larus livens can also be an aggressive predator, preying on other small-sized species and chicks of inter- and conspecifics $[27,28]$ and is highly aggressive in defending the nesting area [26]. In contrast to most gull species, spatial disposition of nesting pairs within the colony is not clustered, so some breeders could also show nesting separated from the colony in isolated pairs, behaving more territorial than colonial gulls [23,25]. Related to the subject of this study, the species has been recorded as confronting drones aggressively during the breeding stage [29] in some cases shooting down some drones in the breeding area as recorded in other species of the genus Larus [18].

Therefore, the aim of this study was to depict and evaluate the response of a seagull species during the non-breeding season (at their maximal spread) to a small-sized drone in the urban area and natural surroundings (usually used for recreational purposes) where the use of this kind of technology has often been recorded. The reaction of the species was examined, predicting that (1) drone sounds trigger in gulls a confronting reaction in response to a disturbance reaction; (2) gulls occurring in urbanized areas are more tolerant to drones, decreasing their antagonizing reaction, consequently, plasticity and adaptation of the opportunistic species to urban environments [30]; (3) larger groups tend to display an aggressive reaction more often in response to social cohesion; and finally (4) adults confront the drone more frequently rather than juveniles in response to higher intragroup territorial dominance.

\section{Material and Methods}

\subsection{Study Area}

The study area comprises urban and pristine coastal areas where the use of recreational drones has been recorded in the last four years in La Paz and surroundings in Baja California Sur, México (Figure 1), which are populated by approximately 301,900 inhabitants, with an increasing population rate of 18.5\% since 2010 (setuesbsc.gob.mx, accessed on 26 March 2021). Tourism is an important economic activity in the area, where the number of visitors has increased $65 \%$ in the last five years (setuesbsc.gob.mx, accessed on 26 March 2021). Recreational coastal areas include tourism and fishing activities of low scale impact (aquaculture, artisanal fishing, etc.). Recreational beaches are distributed 
throughout most of the urbanized area of La Paz and in less impacted in the northward and southward areas. The climate is arid tropical with mean annual temperature of $22.8^{\circ} \mathrm{C}$ $\left(9^{\circ} \mathrm{C}-35^{\circ} \mathrm{C}\right)$ and a monsoon regime with a mean annual rainfall of $175 \mathrm{~mm}$. The coastal areas are characterized by sand and mud intertidal floodplains with marsh vegetation and mangrove swamps mainly in Ensenada de La Paz, and open sandy and rocky beaches surrounded by hills that do not exceed $100 \mathrm{~m}$ covered by xerophilous scrub [31].

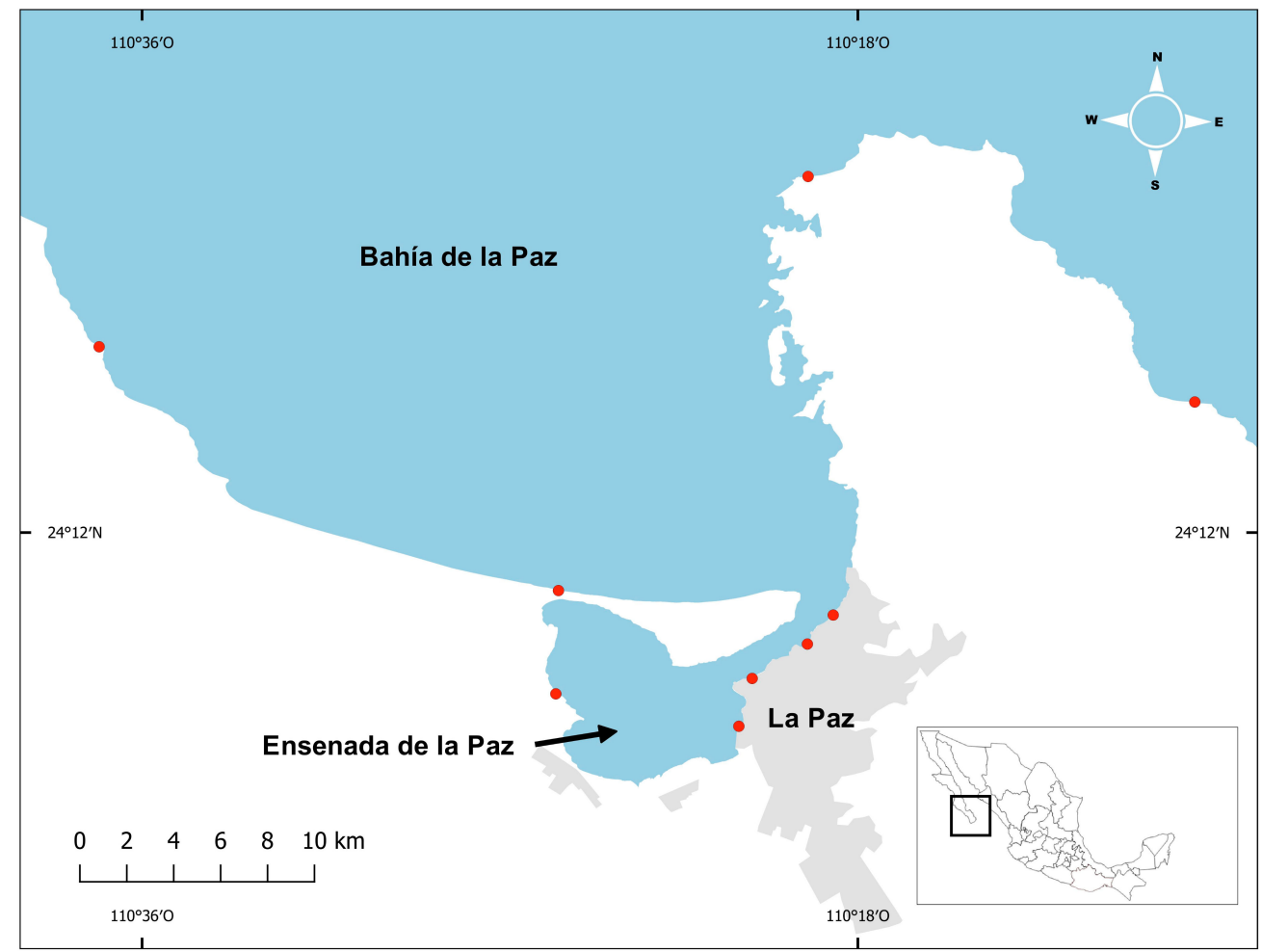

Figure 1. Areas where the drone was utilized to record Larus livens behavior (red points) in the city of La Paz and coastal surroundings in the Gulf of California during 2019 and 2020 in Baja California Sur, Mexico.

\subsection{Field Work and Analysis}

The effect of UAVs in L. livens behavior was examined after the breeding season from late spring to winter (May-February). Gull behavior was recorded from 10:00 to 14:00 $\mathrm{h}$ in several coastal areas of La Paz and surroundings (Figure 1). A drone (SPARK, DJI Technology) from a group of small and quiet drones among the DJI models was used. The drone weighed $300 \mathrm{~g}$, sound was approximately $78 \mathrm{~dB}$, was mostly dark gray colored with a white top cover, operated under direct pilot control using a standard two-stick radio controller, and mediated by DJI GO software application. To record the species reaction to the UAVs, the focus was on individuals present on several beaches along the study area. Several coastal spots in the urban area and natural surroundings (Figure 1) were selected where the use of drones is habitual for recreational purposes and has been recently recorded. The detectable individuals were counted from the spot where the drone would land and turn on (5-20 m from the shoreline), and plumages differencing adults from juveniles were determined. Distance between individuals and the selected spot in land for take-off were also estimated with a rangefinder (Bushnell $10 \times 25 / 5-700$ ). Once the drone was initiated, gull reactions were recorded if they displayed an agonistic behavior. Agonistic behavior was considered as a direct flight from a gull confronting the drone, around and over the device as close as $0.3 \mathrm{~m}$, and with an intense vocalization. Thus, this type of behavior was recorded if the gull reacted once the (1) rotors started and (2) the drone took off in vertical flight until the device reached $20 \mathrm{~m}$ high. Once the drone rose $20 \mathrm{~m}$, a 2-min frame was expected for any reaction; after that, the drone was landed. If 
the reaction was recorded as aggressive, the drone was landed immediately to avoid any injury to the device by the gulls.

Lineal observation distances were evaluated from the nucleus of the urban area of coastal La Paz, if they were related with agonistic reactions. Gull behavior was also analyzed in function of the distance of individuals to the drone, season, number of adults and juveniles, and total number of gulls independent of plumage. Reactions by gulls were also evaluated in response to UAV colors. In this sense, the response to the drone was measured in light (white) and dark (blue and black) color models.

\subsection{Statistical Analysis}

Group size was compared between urbanized and scarce or without urbanization areas throughout the Mann-Whitney-Wilcoxon test taking into account total individual, adult, and juvenile plumages. A selection model analysis fitting a generalized linear model (GLM) was used with binomial distribution to evaluate the potential mobbing behavior explanatory variables by applying the Akaike Criterion Analysis for a reduced number of samples (AICc) [32]. Statistical analyses were conducted using "MASS", "car" and "AER" packages and "ggplot2" for figures in R software version 4.0.1 (R Core Development Team, 2020). Geospatial analysis was elaborated with the QGis software version 2.1.8.

\section{Results}

Individuals $(\mathrm{N}=139)$ of $L$. livens (84 adults and 55 juveniles) were recorded in the close surroundings where the drone was utilized to measure the gulls' reactions. Group size was 3.4 individuals globally (range 1-13, SD 3.5), composed of 2.2 adults (range 1-10, SD 1.8) and 1.1 sub-adults and juveniles (range 0-12, SD 2.5) per group. Urbanized areas showed 4.1 individuals (range 1-12, SD 4.1) per group, similar to 3.6 (range 1-13, SD 3.5) individuals of natural areas (W=171.5, $p=0.9$,) since group size of total individuals (TGS) and number of adults (AGS) and juveniles (JGS) were also similar between both areas ( $\mathrm{W}=170.5, p=0.9$, and $\mathrm{W}=158.5, p=0.7$, respectively). Once the drone landed and turned on in land, gulls did not evidence any reaction to its sound or presence in any case. Gulls only reacted when the drone was in ascendant movement once it took off, when the agonistic behavior was recorded and characterized as a "mobbing" reaction. The mobbing reaction includes vocalizations and aggressive movements against the drone, which could start as far as more than $200 \mathrm{~m}$ since individuals had detected the drone. Once vocalizations started, individuals flew straight to the area were the drone was flying. Individuals that initiated mobbing actions were all gulls with adult plumage, which displayed accelerated flights toward the drone always from above. Once adults reacted against the drone, juveniles and sub-adults joined in the display although less aggressively than adults and in the outer space of the mobbing display. The best GLM model selected by AICc (Table 1$)$ evidenced the distance from urban areas $(Z=2.7 ; p=0.006)$ and interaction between total group size and number of adults as the most important variables that better explained the reaction against the drone $\left(\mathrm{Z}=-1.8 ; p=0.06 ; D^{2}=58.2 \%\right)$. Clearly, gulls increased mobbing displays in distant areas from the city of La Paz (Figure 2) and when group size became smaller with a scarce number of adults (Figure 3). Most of the agonistic displays against the drone were conducted by adult pairs, whose aggressive behavior was absent when groups were formed by more than three adults (Figure 3). Variables such as distance of gulls from the spot where the drone took off, drone color, season, and number of juveniles, were discarded as explanatory variables of agonistic reactions. 
Table 1. Five top models selected by the Akaike Selection Criterion using AIC (AIC) for mobbing displays of the Larus livens in response to the presence of the drone in La Paz and surroundings, Baja California Sur, Mexico. (TGS = group size, AGS = adults group size, JGS = juveniles group size, DC = distance to the nearest city, $\mathrm{S}=$ season, $\mathrm{DI}=$ distance drone-individuals, and $\mathrm{QC}=$ drone color).

\begin{tabular}{cccccc}
\hline Model & df & logLik & AICc & $\Delta$ AICc & Weight \\
\hline 1) DC + AGS × TGS & 5 & -10.4 & 32.8 & 0 & 0.238 \\
2) DC + TGS & 3 & -13.6 & 34.1 & 1.27 & 0.126 \\
2) DC $\times$ AGS & 4 & -12.6 & 34.6 & 1.81 & 0.097 \\
2) DC + TGS + JGS & 4 & -13 & 35.4 & 2.59 & 0.065 \\
3) DC + AGS & 3 & -14.3 & 35.5 & 2.68 & 0.062 \\
\hline
\end{tabular}

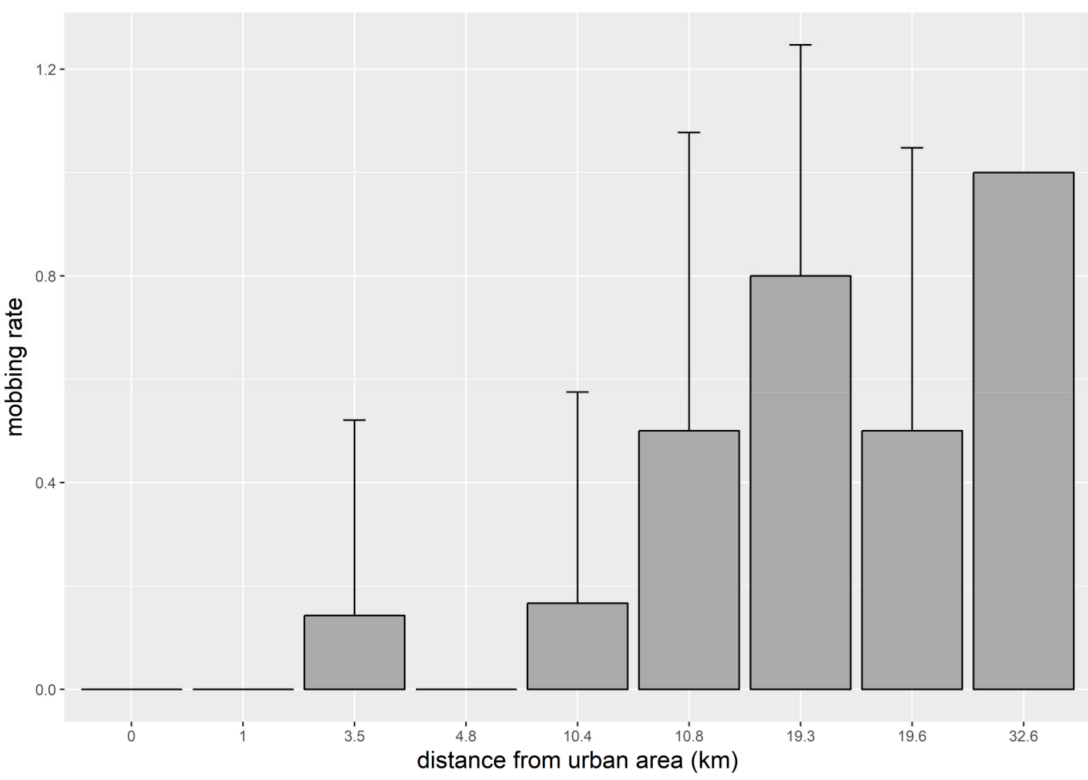

Figure 2. Mobbing rate of Larus livens related to distance from the central area of the urban matrix of La Paz, Baja California Sur, Mexico.

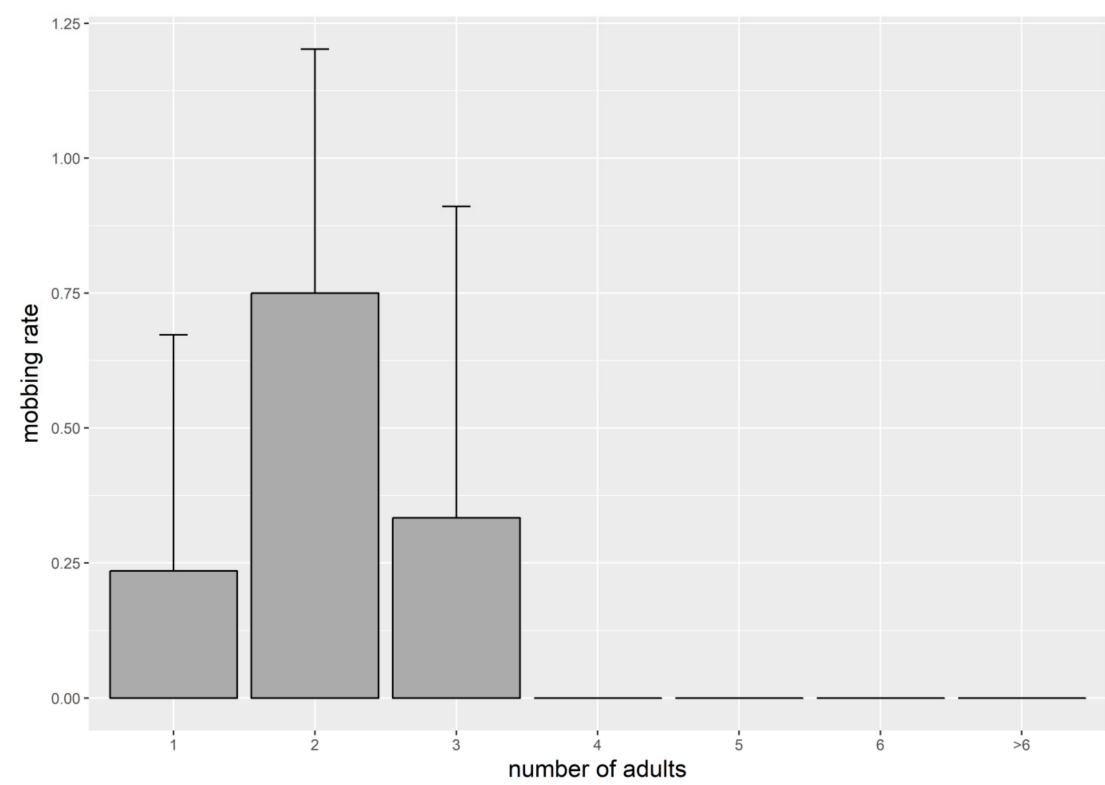

Figure 3. Mobbing rate of Larus livens related to the number of adults within the group of gulls in the La Paz urban matrix and surroundings, Baja California Sur, Mexico. 


\section{Discussion}

Negative reactions to drones have been evaluated in several marine species of different taxa, which were present in a few species in marine environments. Most of these reactions were recorded in birds during the breeding season in species highly sensitive to disturbance and sometimes with an intense territorial behavior $[16,18]$. During breeding, other studies have suggested that breeders react to flying movements rather than sound disturbance [33]. In this study, as other authors have suggested, the drone sound did not reflect any negative reaction from the gulls, evidencing vertical movement as the cause that triggers the mobbing display. Additionally, the reactions did not differ among different colors, which also verified that gulls react in response to the flying drone dynamics. On the response of small size birds as passerines to the drone shape, research evidenced a lower reaction from birds to a DJI Phantom drone (weight: 1391 g, size: $28.9 \times 28.9$, sound: over $85 \mathrm{~dB}$ approximately) compared with models that simulated a predator with a raptor silhouette [33]. Evidently because of the reduced size of the device $(13.9 \times 13.9 \mathrm{~cm})$, the drone may not be perceived by this large gull as a threat for their survival. The gulls' reaction in response to the limited movements conducted by drones (vertical movement to $20 \mathrm{~m}$ high and posterior landing) in this study reflect how aggressive this species can be with "non-classified" objects flying in their territories.

Larus livens shows an aggressive territorial behavior during breeding, displaying pronounced agonistic reactions among individuals of the same breeding colony or even more intense when pairs nest isolated $[23,25]$. Breeding pairs and juveniles leave the breeding area once juveniles can fledge, although dispersion does not mean that some breeders finish their territorial reactions outside the breeding area. Gulls were highly reactive to the drone in recreational non-urbanized areas. These reactions geospatially agreed with agonistic displays by adults against other conspecifics, mostly to other adults (less frequent with sub-adults) including vocalization and active expulsion from the area by chasing them.

Agonistic displays were not recorded against juveniles, whose presence was generally accepted by adults in all areas and sometimes were the target of the begging display of fledged juveniles. In fact, this display was sometimes so intense that adults tried to stay apart from them. Juveniles and sub-adults in these recreational non-urbanized areas acted as secondary actors during mobbing reactions against the flying drone. They vocalized and overflew in the marginal area of the mobbing group while adults (mostly pairs) were the closest to the drone. This coincident agonistic behavior in both cases (between conspecifics and adults confronting drones) in the same area suggest that territoriality could be expressed during the non-breeding stage where feeding resources are scarcer, less predictable, and less varied than in urbanized areas [34]. In urbanized areas, no aggressive reaction by gulls was recorded against the drone and coincidently, neither was any agonistic reaction recorded between conspecifics in these areas.

Coastal environments can congregate numerous seabird species along the shoreline, which are adapted to exploit the resources in this transitional area between terrestrial and marine environments. Larus genus gulls are generally among the coastal seabirds that take advantage of coastal urbanity; they forage over urban refuse dumps [35], artisanal, industrial, and recreational fisheries discards [36] as well as waste in recreational touristic areas [37]. Larus livens can be considered among these kind of synanthropic gulls that take advantage of different kinds of human waste [25] and have settled in touristic areas and coastal cities of the Gulf of California. In contrast to other gulls, L. livens has been shown to be one of the most aggressive and territorial species of the genre, probably in response to competence that could bring a high diversity and abundance of scavenger, kleptoparasitic, and piscivorous coastal species inhabiting in the area [38]. This last one could increase while in the non-breeding stage when other wintering migrant species arrive in the area, enlarging the abundance of potential competitors.

The broader species spectrum in higher trophic levels could magnify competition, resulting in trophic niche reduction of these species as measured, for example, in other 
scavengers [39]; this last one could result in amplifying territorial behaviors. In contrast, a close related species such as Larus dominicanus inhabits coastal areas in southern Argentina where scavengers and other kleptoparasitic species are scarce; competence for food could be considered low, and populations are expanding to several areas including terrestrial habitats, also exploiting these resources during the non-breeding stage [40]. This abundant human subsidized scavenger of Patagonia did not evidence any reaction to the presence of drones, even in breeding colonies when the species is expected to be more reactive (Frixione, personal communication 2015). On the other hand, L. livens, was evidenced to be more reactive to drone presence in their non-urbanized territories. These distant recreational areas from the city are occupied by territorial individuals that may be partially subsidized by human recreational refuse. This situation could improve wintering survival of these individuals, although this dietary complement fluctuates and is not be as predictable and abundant as in the urban coastal area.

Even when these recreational areas can attract gulls by human refuse, these resources could be scarcer than in urban areas but more valuable, increasing agonistic behaviors and displaying territorial reactions against potential competitors more frequently. In contrast, synanthropic species in urban areas modify their natural behavior, reducing dispersal and migratory patterns besides decreasing intraspecific aggression and competence [41,42], especially in opportunistic gull species [37,43]. In light of the results, the use of drones could be considered as safe and viable in coastal central urban areas, increasing risks of $L$. livens aggressive reactions in recreational coastal spots apart from the city. This last one could be of interest if the activity of delivery by drones is developed in the area, considering un-urbanized coastal areas as places where drones could trigger agonistic and disturbance reactions by territorial species. These peripheral areas could be used by drone delivery systems in the near future. For example, they may provide medical supplies or commercial delivery in terrestrial areas in the coast or at sea, either islands or any kind of vessel. Future flying routes utilized by drones should be designed considering the presence of territorial seabirds or other fauna. These kinds of problematic interactions should be avoided because they could affect delivery or normal seabird behavior.

Further research should be performed in non-urbanized coastal areas inquiring about the reactions of different seabird species in diverse environments, flying route design, and other specific flight and drone characteristics. Several kinds of territorial birds take advantage of artificial light and other anthropic resources produced by urbanization, especially in open habitat spaces designed for recreation included in the urban matrix. Thus, in-depth studies are also recommended during night-time in several areas when nocturnal birds become active in cities.

\section{Conclusions}

As previously mentioned, physical characteristics (as colors) and sound did not evidence an agonistic reaction by L. livens against the drone. The distance between gulls and where the drone took-off was not correlated with a negative reaction by this species. Agonistic behaviors were associated with vertical movement of the vehicle once the drone took off, triggering the reaction classified as mobbing. Generally, mobbing displays were extremely close to the drone and clearly against it more frequent in groups conformed by two adults evidencing some kind of territorial behavior. This agonistic reaction was also more frequent in un-urbanized areas rather than in urban areas. To conclude, coastal urban areas can be considered as free risk environments for small drones by this aggressive species, increasing the risk in recreational non-urban areas where gulls could be more aggressive during non-breeding stages.

Supplementary Materials: The following are available online at https:/ /www.mdpi.com/article/10 .3390/drones5020030/s1.

Author Contributions: Conceptualization, M.G.F. and C.S.; methodology, M.G.F.; validation, M.G.F. and C.S.; formal analysis, M.G.F. and C.S.; investigation, M.G.F. and C.S.; resources, M.G.F. and C.S.; 
writing—original draft preparation, M.G.F.; writing—review and editing, C.S. All authors have read and agreed to the published version of the manuscript.

Funding: This research received no specific grant from any funding agency, commercial, or not-forprofit sectors.

Data Availability Statement: Data is contained within the supplementary material.

Acknowledgments: The authors would like to thank Consejo de Ciencia y Tecnología (CONACYT) for the support of its Professorship program "Catedras" and PhD scholarship, and the Universidad Autónoma de Baja California Sur (UABCS) for the partial support of the publication charge.

Conflicts of Interest: None.

Ethical Standards: This work conforms to national, local, and institutional laws and requirements.

\section{References}

1. Anderson, K.; Gaston, K.J. Lightweight Unmanned Aerial Vehicles Will Revolutionize Spatial Ecology. Front. Ecol. Environ. 2013, 11, 138-146. [CrossRef]

2. Park, J.; Kim, S.; Suh, K. A Comparative Analysis of the Environmental Benefits of Drone-Based Delivery Services in Urban and Rural Areas. Sustainability 2018, 10, 888. [CrossRef]

3. Wang, Z.; Griffin, A.; Lucas, A.; Wong, K.C. Psychological warfare in vineyard: Using drones and bird psychology to control bird damage to wine grapes. Crop Prot. 2019, 120, 163-170. [CrossRef]

4. Joshi, E.; Sasode, D.S.; Singh, N.; Chouhan, N. Revolution of Indian Agriculture through Drone Technology. Biot. Res. Today 2020, 2, 174-176.

5. Hodgson, J.C.; Baylis, S.M.; Mott, R.; Herrody, A.; Clarke, R.H. Precision wildlife monitoring using unmanned aerial vehicles. Sci. Rep. 2016, 6, 22574. [CrossRef] [PubMed]

6. Butcher, P.A.; Colefax, A.P.; Gorkin, R.A.; Kajiura, S.M.; López, N.A.; Mourier, J.; Purcell, C.R.; Skomal, G.B.; Tucker, J.P.; Walsh, A.J.; et al. The Drone Revolution of Shark Science: A Review. Drones 2021, 5, 8. [CrossRef]

7. Stankov, U.; Kennell, J.; Morrison, A.M.; Vujičić, M.D. The view from above: The relevance of shared aerial drone videos for destination marketing. J. Travel Tour. Mark. 2019, 36, 808-822. [CrossRef]

8. Provost, E.J.; Butcher, P.A.; Coleman, M.A.; Kelaher, B.P. Assessing the viability of small aerial drones to quantify recreational fishers. Fish. Manag. Ecol. 2020, 27, 615-621. [CrossRef]

9. Maza, I.; Caballero, F.; Capitán, J.; Martínez-de-Dios, J.; Ollero, A. Experimental results in multi-UAV coordination for disaster management and civil security applications. J. Intell. Robot. Syst. 2011, 61, 563-585. [CrossRef]

10. Shavarani, S.M.; Nejad, M.G.; Rismanchian, F.; Izbirak, G. Application of hierarchical facility location problem for optimization of a drone delivery system: A case study of Amazon prime air in the city of San Francisco. Int. J. Adv. Manuf. Technol. 2018, 95, 3141-3153. [CrossRef]

11. Yakushiji, K.; Fujita, H.; Murata, M.; Hiroi, N.; Hamabe, Y.; Yakushiji, F. Short-Range Transportation Using Unmanned Aerial Vehicles (UAVs) during Disasters in Japan. Drones 2020, 4, 68. [CrossRef]

12. Sedov, L.; Krasnochub, A.; Polishchuk, V. Modeling quarantine during epidemics and mass-testing using drones. PLoS ONE 2020, 15, e0235307. [CrossRef]

13. Muller, C.G.; Chilvers, B.L.; Barker, Z.; Barnsdale, K.P.; Battley, P.F.; French, R.K.; McCullough, J.; Samandari, F. Aerial VHF tracking of wildlife using an unmanned aerial vehicle (UAV): Comparing efficiency of yellow-eyed penguin (Megadyptes antipodes) nest location methods. Wildl. Res. 2019, 46, 145-153. [CrossRef]

14. Girault, C. Between naturalness and urbanity, how are protected areas integrated into cities? The case of Helsinki (Finland). J. Urban Res. 2017, 16. [CrossRef]

15. Floreano, D.; Wood, R.J. Science, technology and the future of small autonomous drones. Nature 2015, 521, 460-466. [CrossRef]

16. Barr, J.R.; Green, M.C.; De Maso, S.J.; Hardy, T.B. Drone surveys do not increase colony-wide flight behaviour at waterbird nesting sites, but sensitivity varies among species. Sci. Rep. 2020, 10, 3781. [CrossRef]

17. Rümmler, M.; Mustafa, O.; Maercker, J.; Peter, H.; Esefeld, J. Measuring the influence of unmanned aerial vehicles on Adélie penguins. Polar Biol. 2016, 39, 1329-1334. [CrossRef]

18. Brisson-Curadeau, É.; Bird, D.; Burke, C.; Fifield, D.A.; Pace, P.; Sherley, R.B.; Elliott, K.H. Seabird species vary in behavioral response to drone census. Sci. Rep. 2017, 7, 17884. [CrossRef] [PubMed]

19. Kim, S.J.; Lim, G.J.; Cho, J.; Côté, M.J. Drone-Aided Healthcare Services for Patients with Chronic Diseases in Rural Areas. J. Intell. Robot. Syst. 2017, 88, 163-180. [CrossRef]

20. Afán, I.; Máñez, M.; Díaz-Delgado, R. Drone Monitoring of Breeding Waterbird Populations: The Case of the Glossy Ibis. Drones 2018, 2, 42. [CrossRef]

21. Francis, R.J.; Lyons, M.B.; Kingsford, R.T.; Brandis, K.J. Counting mixed breeding aggregations of animal species using drones: Lessons from waterbirds on semi-automation. Remote Sens. 2020, 12, 1185. [CrossRef] 
22. Mesquita, G.P.; Rodríguez-Teijeiro, J.D.; Wich, S.A.; Mulero-Pázmány, M. Measuring disturbance at a swift breeding colonies due to the visual aspects of a drone: A quasi-experiment study. Curr. Zool. 2020, 67, 157-163. [CrossRef] [PubMed]

23. Spear, L.B.; Anderson, D. Nest-site selection by Yelow-footed Gulls. Condor 1989, 91, 91-99. [CrossRef]

24. Lozano, E.; Carmona, R.; Brabata, G. Reproductive success of Heermann's (Larus heermanni) and Yellow-footed (L livens) gulls in the south of the gulf of California, Mexico. Ornitol. Neotrop. 2004, 15, 237-246.

25. Hand, J.L.; Hunt, G.L.; Warner, M. Thermal stress and predation: Influences on the structure of gull colony and possibly on breeding distributions. Condor 1981, 83, 193-203. [CrossRef]

26. Hand, J.L. Human disturbance in Western Gulls Larus occidentalis livens colonies and possible implication by intraespecific predation. Biol. Conserv. 1980, 18, 59-63. [CrossRef]

27. Baird, R.W. Yellow-footed gull (Larus livens) preys on black storm-petrel (Oceanodroma melania). Colonial Waterbirds 1996, 19, 260-261. [CrossRef]

28. Flores-Martínez, J.; Gerardo-Herrera, L.; Arroyo-Cabrales, J.; Alarcón, I.; Ruiz, E.A. Seasonal dietary differences of the Yellowfooted Gull (Charadriiformes: Laridae) in Isla Partida Norte, Gulf of California, Mexico. Rev. Mex. Biodivers. 2015, 86, 412-418. [CrossRef]

29. Adame, K.; Pardo, M.A.; Salvadeo, C.; Beier, E.; Elorriaga-Verplancken, F.R. Detectability and categorization of California sea lions ussing an anmanned aerial vehicle. Mar. Mammal Sci. 2017, 33, 913-925. [CrossRef]

30. Lowry, H.; Lill, A.; Wong, B.B. Behavioural responses of wildlife to urban environments. Biol. Rev. Camb. Philos. Soc. 2013, 88, 537-549. [CrossRef] [PubMed]

31. Salgado, R.A.; Bermejo, N.M.; Playa, C.; de Santa Rita, P.; La Paz, B.; de La Paz, H.M.; Esta, F.I.; Vértice, X.Y. Ficha Informativa de los Humedales de RAMSAR (FIR). 2008. Available online: https:/ / rsis.ramsar.org/RISapp/files/RISrep/MX1335RIS.pdf (accessed on 26 March 2021).

32. Akaike, H. Information Theory and an Extension of the Maximum Likelihood Principle. In International Symposium on Information Theory; Petrov, B.N., Csaki, F., Eds.; Springer: New York, NY, USA, 1973; pp. 267-281.

33. Egan, C.C.; Blackwell, B.F.; Fernández-Juricic, E.; Klug, P.E. Testing a key assumption of using drones as frightening devices: Do birds perceive drones as risky? Condor 2020, 122. [CrossRef]

34. Spelt, A.; Williamson, C.; Shamoun-Baranes, J.; Shepard, E.; Rock, P.; Windsor, S. Habitat use of urban-nesting lesser black-backed gulls during the breeding season. Sci. Rep. 2019, 9, 10527. [CrossRef] [PubMed]

35. Kasinsky, T.; Suárez, N.; Marinao, C.; Yorio, P. Kelp Gull (Larus dominicanus) Use of Alternative Feeding Habitats at the Bahía San Blas Protected Area, Argentina. Waterbirds 2018, 41, 285-294. [CrossRef]

36. Marinao, C.; Kasinsky, T.; Suárez, N.; Yorio, P. Contribution of recreational fisheries to the diet of the opportunistic Kelp Gull. Austral Ecol. 2018, 43, 861-875. [CrossRef]

37. Nunes, L.J.; Raposo, M.A.; Gomes, C.J. The Impact of Tourism Activity on Coastal Biodiversity: A Case Study at Praia da Cova Redonda (Algarve-Portugal). Environments 2020, 7, 88. [CrossRef]

38. Marrón, G.; Carmona, R.; Ayala, V.; Gutiérrez, G. Noteworthy records of waterbirds in La Paz Bay, Baja California Sur, Mexico. Huit. Rev. Mex. Ornitol. 2014, 15, 57-63.

39. Silverthorne, K.M.; Perrig, P.L.; Lambertucci, S.A.; Pauli, J.N. Isotopic Niche Partitioning in Avian Scavenger Communities of South America. J. Raptor Res. 2020, 54, 440-446. [CrossRef]

40. Lisnizer, N.; Yorio, P. Trophic niche expansion during the non-breeding season in kelp gulls of known breeding colony. Mar. Biol. 2019, 166, 12. [CrossRef]

41. Sol, D.; González-Lagos, C.; Moreira, D.; Maspons, J.; Lapiedra, O. Urbanisation tolerance and the loss of avian diversity. Ecol. Lett. 2014, 17, 942-950. [CrossRef]

42. Birnie-Gauvin, K.; Peiman, K.S.; Gallagher, A.J.; de Bruijn, R.; Cooke, S.J. Sublethal consequences of urban life for wild vertebrates. Environ. Rev. 2016, 24, 416-425. [CrossRef]

43. Brousseau, P.; Lefebvre, J.; Giroux, J.F. Diet of ring-billed gull chicks in urban and non-urban colonies in Quebec. Colonial Waterbirds 1996, 19, 22-30. [CrossRef] 